\title{
INFLUÊNCIAS DA EDUCAÇÃO AMBIENTAL, DO GRAU DE ESCOLARIDADE E DO AMBIENTE DE TRABALHO EM PRÁTICAS AMBIENTAIS POR TRABALHADORES NA INDÚSTRIA
}

Leonardo Turazzi Tramontina ${ }^{1}$

Irene Carniatto ${ }^{2}$

Resumo: Apresenta-se um estudo de caso sobre hábitos dos trabalhadores da indústria em separar os resíduos reciclados. Busca-se também averiguar se as origens dessas atitudes estão relacionadas com o nível de escolaridade ou práticas ambientais em seus locais de trabalho. O método adotado foi o exploratório-descritivo e in loco operacionalizado por estudo de caso, desenvolvido com operários de 13 indústrias distintas do Parque Moveleiro da cidade de Toledo-PR. Foram entregues 70 questionários, dos quais, foram obtidos 53 respondidos, a fim de compreender a percepção daqueles quanto aos problemas ambientais que afetam o Planeta. Os dados demonstraram uma tendência dos trabalhadores que possuem maior nível de escolaridade a apresentarem maior sensibilidade às questões ambientais bem como os que possuem incentivos e exemplos no ambiente de trabalho a fazerem o mesmo em suas casas.

Palavras-chave: Educação Ambiental; Sustentabilidade; Reciclagem; Formação Acadêmica.

\footnotetext{
${ }^{1}$ Academico de Ciências Biológicas da Universidade Estadual Oeste do Paraná (UNIOESTE). E-mail: leotramontina@hotmail.com

${ }^{2}$ Docente e Pesquisadora do Programa de Doutorado e Mestrado em Desenvolvimento Rural Sustentável e Ciências Biológicas da UNIOESTE. E-mail: irenecarniatto@gmail.com
}

Revbea, São Paulo, V. 14, № 1: 29-48, 2019.

revista brasileira educação ambiental 


\section{Introdução}

A preocupação com o meio ambiente e a sustentabilidade ambiental é cada vez mais evidente em nossa sociedade e deixa nítida a importância quanto à separação de lixo e à destinação adequada com o uso da coleta seletiva. Em nosso país, há maior reconhecimento no que se refere às vantagens dessa prática, mas ainda é extremamente prematuro (PEIXOTO; CAMPOS; D'AGOSTO, 2005).

Alves et al. (2012) explicam que a separação de resíduos no Brasil remonta ao ano de 1880, com o Imperador D. Pedro II no Rio de Janeiro e o Decreto, executado por Aleixo Gary e posteriormente por Luciano Francisco Gary, origem da qual temos a designação popular de "gari" para aqueles que limpam e zelam pela cidade.

Nos dias atuais, o governo e a sociedade têm buscado alternativas para minimizar os impactos que causam a desenfreada poluição dos resíduos sólidos produzidos pelo homem, e ainda investir na reutilização ou reaproveitamento do que há no lixo. Peixoto, Campos e D'Agosto (2005) explicam que, no Brasil, os municípios têm a responsabilidade de separar e coletar lixo e alguns municípios criaram leis que regulamentam a coleta seletiva. Os autores ainda mostram em sua pesquisa com alunos do ensino infantil que mais de $70 \%$ das famílias pesquisadas não se preocupam com a separação do lixo, mas reconhecem-se a influência que tais crianças têm sobre seus pais.

Muito se sabe e tem sido registrado sobre a influência que a escola pode propiciar ao cidadão no que tange ao respeito e cuidado com o meio ambiente. Trindade (2011) demonstrou que professores tendem a incentivar seus alunos a reciclarem e a separarem lixo com o próprio exemplo a partir da coleta seletiva nas escolas. Este mesmo estudo ainda concluiu que atividades como essas criam adultos mais reflexivos e coletivos, que pensam no todo e influenciam quem está a sua volta, portanto, reitera-se a incrível importância da escola como base para a Educação Ambiental.

Os alunos e cidadãos possuem um longo trajeto de construção de suas percepções e noções sobre suas relações com o meio ambiente, as quais estão diretamente ligadas às próprias interpretações e representações que seus tutores ou professores possuíam. Professores com visões antropocêntricas tendem a formar alunos que buscam na Educação Ambiental formas de melhorar a vida da espécie humana, independente dos demais seres que habitam o Planeta. Não obstante, professores com visão globalizante da realidade conseguem formar cidadãos que refletem sobre sua interação e conectividade com o global e buscam preservar, manter, salvar a espécie humana em equilíbrio e em interconexão com os demais seres vivos e não vivos (SAHEB; DA LUZ, 2012).

Com base nestes dados, pode-se imaginar que o cidadão com maior grau de formação educacional consiga ter melhor compreensão e posicionamento quanto à situação global e à necessidade de repensar nossos padrões de consumo.

Revbea, São Paulo, V. 14, № 1: 29-48, 2019. 
Parecem então evidentes a importância e a responsabilidade que a escola tem perante a formação do cidadão com um olhar apurado e sensibilizado em relação aos problemas globais, abordados pela Educação Ambiental. Mas, sabese que, na sociedade, são encontrados cidadãos com visões corretas e conectadas ao todo, e outros também com distorção dos fatos e pouco entendimento sobre $o$ assunto.

Atualmente, temas como escolas, gestores, educadores e alunos em relação às representações ligados à Educação Ambiental são bastante pesquisados e analisados. Mas, estes mesmos alunos, tendo influências daqueles ou não, crescem, se desenvolvem e começam a trabalhar. E será que suas vidas dentro de indústrias e fábricas em geral seguem a mesma vertente de influências obtidas na escola? Ou será que o trabalhador acompanha a visão e a ideologia de suas empresas ou responsáveis por elas?

Em se tratando de fontes influenciadoras, entende-se que o ambiente de trabalho mostra também papel fundamental no dia a dia do cidadão. Bedani (2012) procurou entender relações que poderiam existir dentro do ambiente de trabalho, que incentivassem ou não a criatividade dos funcionários e concluiu que o ambiente teve grande papel influenciador. Vasconcelos (2004), durante sua pesquisa, demonstrou o quanto valores humanos como lealdade, liderança, confiança e outros podem influenciar na felicidade dos funcionários, no ambiente de trabalho e, por conseguinte, torná-los mais interconectados e com produtividade muito maior.

Desta mesma forma, imagina-se que um ambiente de trabalho em que é executada a separação de lixo e feita coleta especializada possa sensibilizar os trabalhadores a fazerem sua parte, e que tal prática se estenda às suas residências e vidas particulares. Lomasso et al. (2015) concluíram que não somente o governo e as escolas, mas também as empresas possuem papel fundamental na soma de esforços para que se construa mais uma cultura de aceitação e aplicação da reciclagem a cada dia.

Nas teses de doutorado, Zamcopé, Ensslin e Ensslin (2009) concluíram que é possível desenvolver um modelo de avaliação de sustentabilidade em indústrias e sua importância para identificar possibilidades e estratégias de melhoria entre as relações da empresa com a sustentabilidade.

Nesta vertente, este estudo buscou compreender melhor a situação de trabalhadores dentro de indústrias e de onde vêm suas influências para agir na separação de lixo reciclável. Foi verificado se aqueles que o fazem, dentro de suas residências e vidas particulares, têm mais influências de acordo com o grau de escolaridade ou aprenderam nas próprias empresas onde trabalham. Além disso, buscou-se levantar as concepções dos entrevistados sobre a finitude dos recursos naturais, a importância do meio ambiente para suas vidas para compreensão da pesquisa e conhecimento do perfil dos pesquisados. 


\section{Objetivos}

- Realizar estudo sobre os hábitos dos trabalhadores da indústria de separação de resíduos reciclados, descobrir se as origens dessas atitudes estão relacionadas com o nível de escolaridade ou com práticas sustentáveis em seu local de trabalho, e relacioná-las aos princípios da Educação Ambiental;

- Verificar o percentual de trabalhadores que têm separado lixo reciclável em suas vidas particulares e levantar outros fatores que podem influenciar as atitudes destes trabalhadores;

- Verificar se as respostas objetivas possuem base ou fundamentação conceitual, comparando-as com as respostas subjetivas do questionário.

\section{Metodologia}

A pesquisa foi desenvolvida no Parque Moveleiro José Luiz Salles, em Toledo, Paraná, Brasil. O método adotado foi o exploratório-descritivo e in loco operacionalizado por estudo de caso, no qual o universo da pesquisa corresponde aos trabalhadores de 13 indústrias distintas que participaram da pesquisa. Foram entregues 70 questionários, dos quais, foram obtidos 53 respondidos e com Termo de Consentimento Livre e Esclarecido, todos assinados. Portanto, os 53 questionários serão considerados como 100\%.

Um questionário fechado e estruturado com 6 questões objetivas e 4 questões subjetivas foi utilizado para coleta dos dados que complementam as objetivas e verificam se o entrevistado soube responder às perguntas com honestidade, integridade e determinado nível de conhecimento. O intuito foi permitir que os participantes fornecessem, de forma indireta, dados que levassem a conclusões sobre suas influências em atitudes perante situações em relação a temas abordados em Educação Ambiental e sustentabilidade, tais como a separação do lixo reciclável em suas casas e no ambiente de trabalho.

De acordo com Amaro, Póvoa e Macedo (2005), um questionário bem elaborado é capaz de conhecer melhor as lacunas e brechas de determinados públicos, e com isso, elaborar medidas como resposta ou ação. Feita a coleta de dados, os questionários foram submetidos a uma análise quantitativa em um primeiro momento e os dados expostos em gráficos comparativos, que evidenciaram algumas relações existentes.

Segundo Manzato e Santos (2012), a análise quantitativa é utilizada para a obtenção de respostas, com determinado público alvo e, por conseguinte, analisada e comparada dentro das estatísticas.

O foco será a tentativa de relacionar os níveis de sensibilidade em relação à sustentabilidade e meio ambiente, com a gestão e ou administração das empresas onde estes funcionários trabalham e possivelmente relacionar suas respostas com seus níveis de escolaridade. As estatísticas por sexo também serão analisadas de forma menos relevante. E será apresentada análise qualitativa das respostas subjetivas do questionário, para verificar se é possível definir se algumas respostas objetivas tiveram fundamentação e base conceitual, ou se os entrevistados preencheram o questionário ao acaso.

Revbea, São Paulo, V. 14, № 1: 29-48, 2019. 


\section{Resultados e Discussão}

O presente estudo abordou o maior número de 70 trabalhadores e operários em Indústrias distintas, dentro do Parque Moveleiro José Luiz Salles, pertencente ao bairro Vila Industrial, da cidade de Toledo, Paraná (Figura 1).

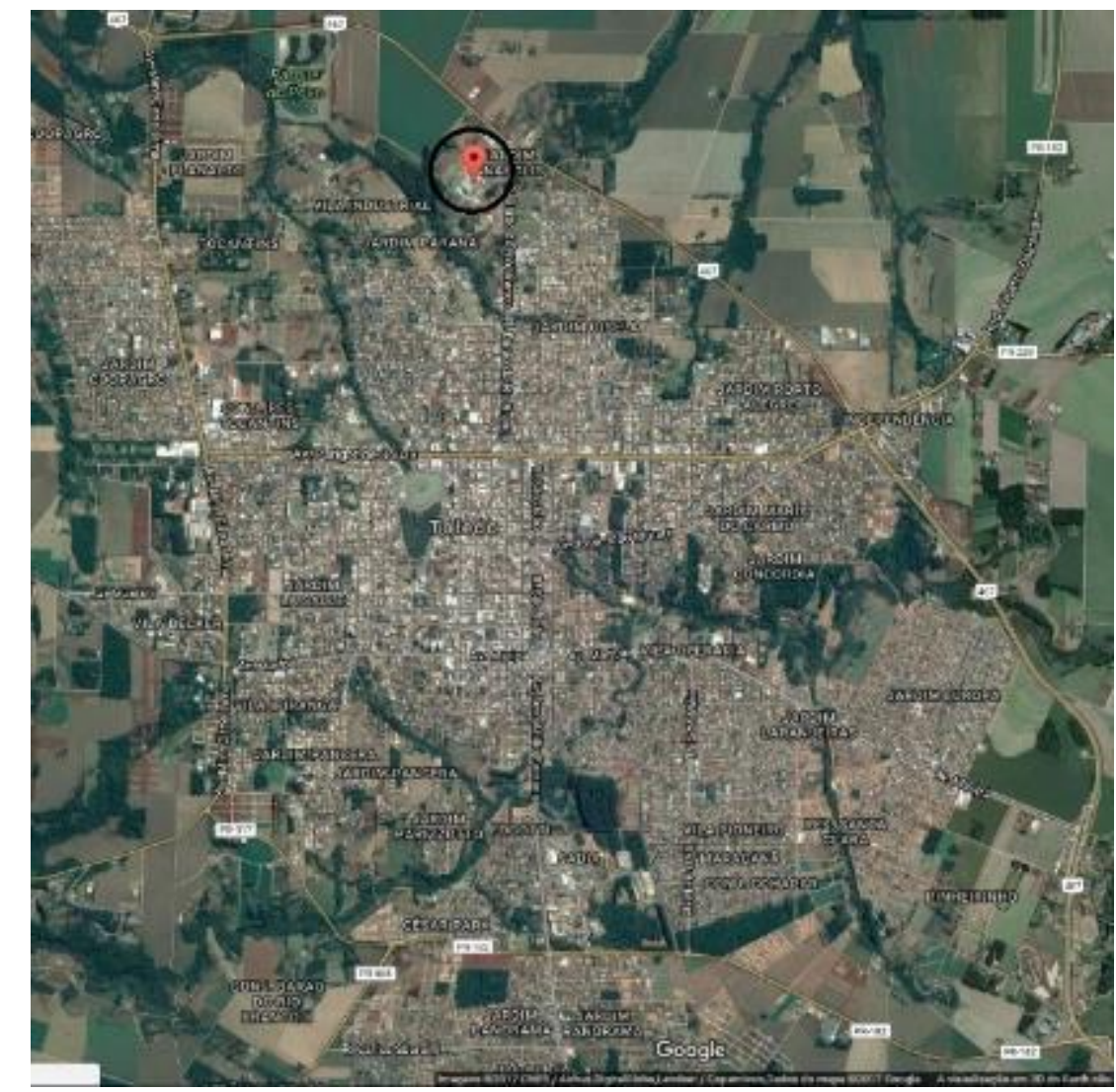

Figura 1: Foto da Cidade de Toledo, Paraná, com a localização do Parque Industrial José Luiz Salles, Vila Industrial. Fonte: Google (2017).

O município de Toledo teve sua população contabilizada em 119.313 habitantes no último censo de 2.010. Estima-se que hoje esteja com aproximadamente 134.000 habitantes. Mais de $70 \%$ da população declara-se como católica, com renda mensal média de 2,5 salários mínimos e taxa de escolarização de 6 a 14 anos de 98,8\%. Tais dados colocam a cidade na posição 83 de 399 dentro do estado e posição 834 dentre as 5.570 cidades do país (IBGE, 2010).

Toledo está hoje no $1^{\circ}$ lugar em Parques Industriais do Oeste do Paraná, com 731 indústrias e mais de 11.500 empresas cadastradas na prefeitura. Conta com $27 \mathrm{CMEls}$ (Centros Municipais de Educação Infantil), com 1.939 crianças matriculadas; 36 escolas municipais de Educação Infantil (Pré-escolar) e Fundamental Séries Iniciais ( $1^{\circ}$ ao $5^{\circ}$ ano), com 7.657 alunos no Ensino Fundamental e 2.920 alunos na Educação Infantil (IBGE, 2010). 
O Parque Moveleiro José Luiz Salles, objeto deste estudo, está localizado nas seguintes coordenadas: -24.700717, -53.741382, no bairro Vila Industrial.

O bairro contabilizou 6.392 habitantes no último censo, dos quais 3.049 habitantes representam a população masculina e 3.343 a feminina, ou seja, uma maioria de $52,3 \%$ são mulheres. Aproximadamente $70 \%$ desta população estão na faixa etária entre 15 e 64 anos de idade. Suas principais ruas são Antônio Comarella, Ângelo Luiz Parizoto, Joaquim Piaza, Hugo Zenni e Mário Marchiori, conforme é possível visualizar na Figura 2.

Foram pesquisadas 13 indústrias distintas com um total de 70 questionários, dos quais, retornaram 53 respondidos. Portanto, os 53 questionários obtidos serão considerados como 100\%.

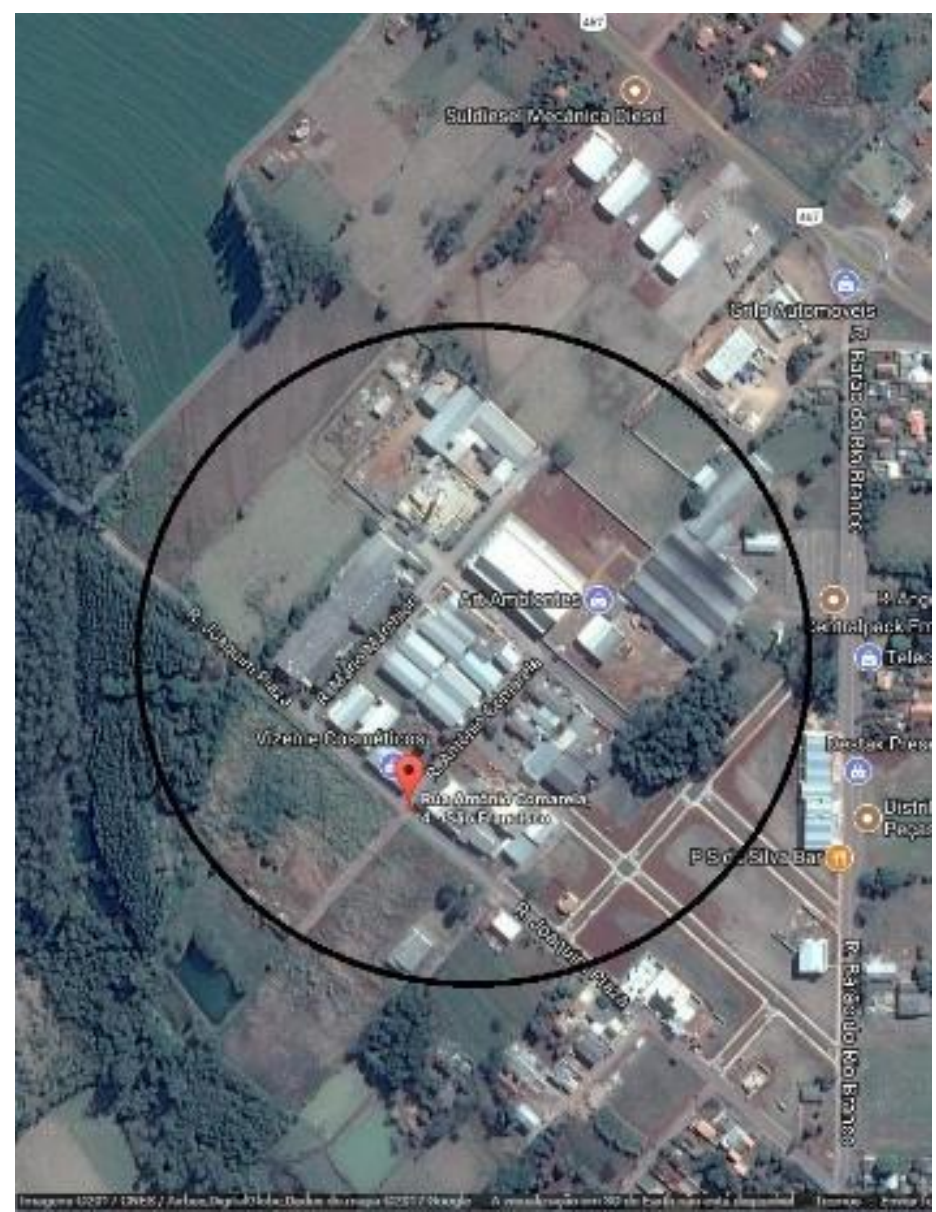

Figura 2: Foto do Parque Industrial José Luiz Salles, Vila Industrial na Cidade de Toledo, Paraná. Fonte: Google (2017).

Dentre o total, 23 possuíam Ensino Médio, 43,3\% e 19 possuíam Ensino Superior, representando $35,8 \%$, registradas na Figura 3. 


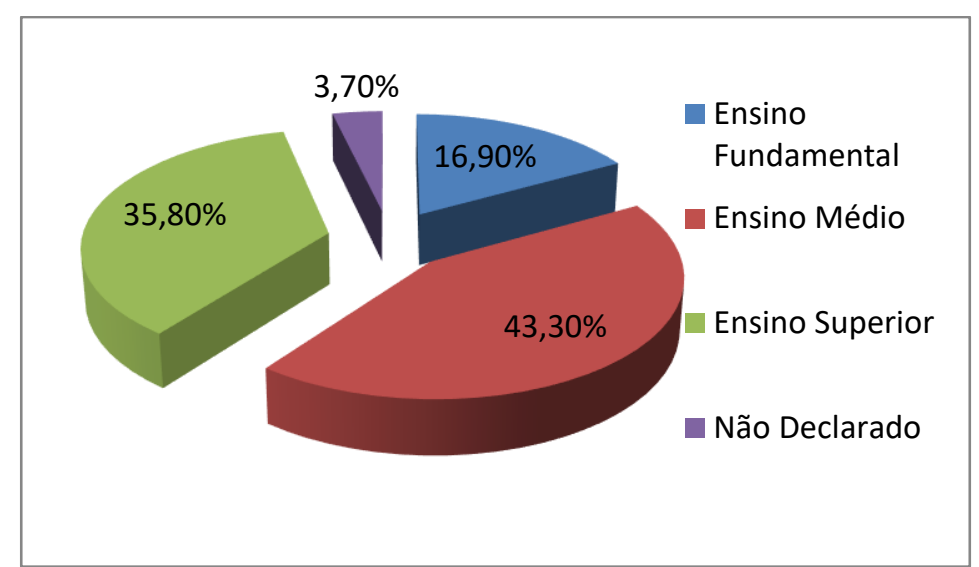

Figura 3: Escolaridade dos trabalhadores das indústrias, Cidade de Toledo, Paraná.

Fonte: Dados desta pesquisa.

Dos 53 participantes, $62,2 \%$ (33 indivíduos) pertenciam ao sexo masculino, 35,8\% (19 indivíduos) ao feminino e 1,8\% (1 indivíduo) não declarou seu sexo, conforme Figura 4. O mais jovem entrevistado registrou 18 anos e o mais velho 66 anos, portanto, os dados apresentaram média etária de 35 anos de idade dos trabalhadores participantes, como mostra a Figura 5.

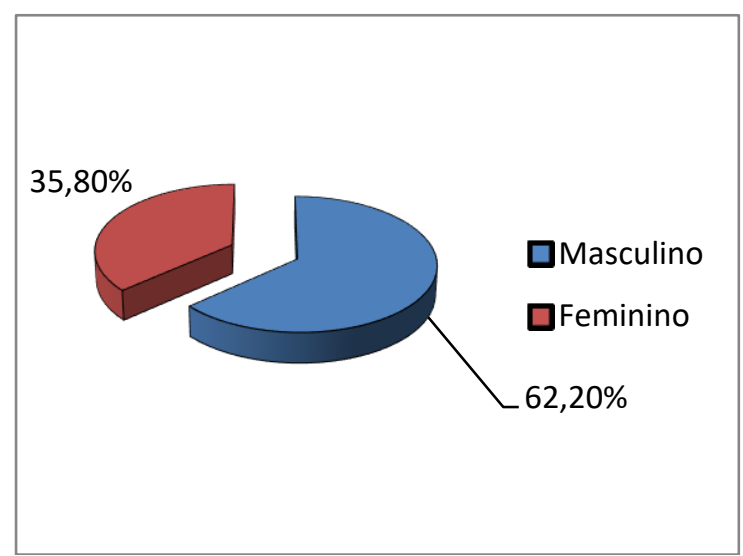

Figura 4: Sexo dos trabalhadores das indústrias, Cidade de Toledo, Paraná.

Fonte: Dados desta pesquisa

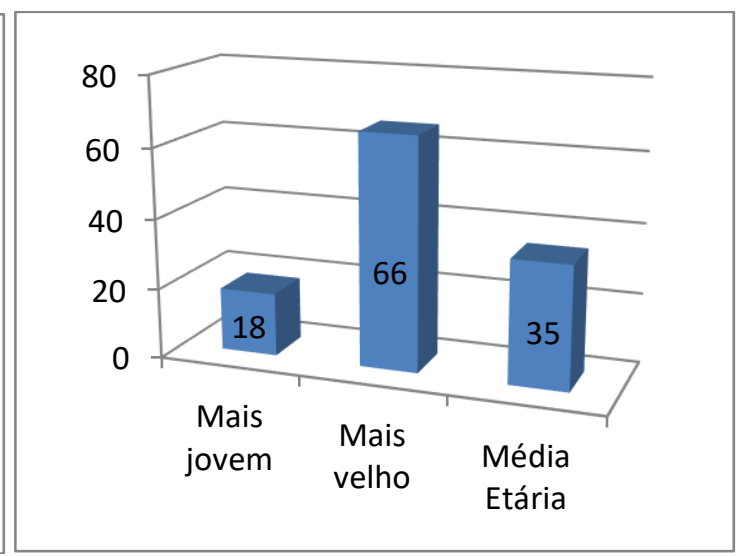

Figura 5: Idade dos trabalhadores das indústrias, Cidade de Toledo, Paraná.

Fonte: Dados desta pesquisa.

A partir da análise das questões, pode-se verificar no primeiro momento de comparação se o entrevistado separa lixo reciclável em sua residência e se tal separação ocorre em seu ambiente de trabalho. Para o sexo masculino, $75 \%$ (25 indivíduos) dos entrevistados declararam separar o lixo reciclável em suas residências e $81 \%$ (27 indivíduos) declaram trabalhar em locais onde é feita a separação do lixo reciclável. Quanto às mulheres, 94\% (18 indivíduos) declararam separar o lixo em casa e 94\% (18 indivíduos) declararam trabalhar em locais onde é feita a separação do lixo. 
Portanto, é possível notar um nível maior de sensibilidade nas respostas do sexo feminino em se tratando de questões ambientais e preocupações com a separação do lixo. Existem também mais empresas que se preocupam com a separação do lixo. Para os indivíduos pesquisados, 94\% das empresas onde as mulheres trabalham e $81 \%$ onde os homens trabalham, do que pessoas, propriamente se preocupam com isso em suas residências, $94 \%$ das mulheres e $75 \%$ dos homens responderam que separam resíduos em suas residências.

Vale lembrar que o intuito deste estudo não será mostrar diferenças entre os gêneros e sim a preocupação com o todo, e com pressupostos de que a educação e o ambiente de trabalho possam influenciar as pessoas. Portanto, a seguir, ocorrem as análises mais gerais, mas sem a preocupação de separar os entrevistados por sexo.

Busca-se avaliar um padrão de respostas que possa revelar se tais trabalhadores têm sido sensibilizados quanto ao cuidado com os resíduos ao longo de sua formação, seja enquanto profissionais ou cidadãos. Os resultados estão em atitudes adequadas quanto à destinação dos resíduos sólidos e à relação de seus níveis de escolaridade e sensibilidade em relação à sustentabilidade e ao meio ambiente.

Em números gerais, sem se preocupar agora com o sexo do entrevistado, obteve-se que $86,7 \%$ (46 indivíduos) trabalham em empresas que separam o lixo e, $81,1 \%$ (43 indivíduos) também separam lixo em suas residências, números representados na Figura 6.

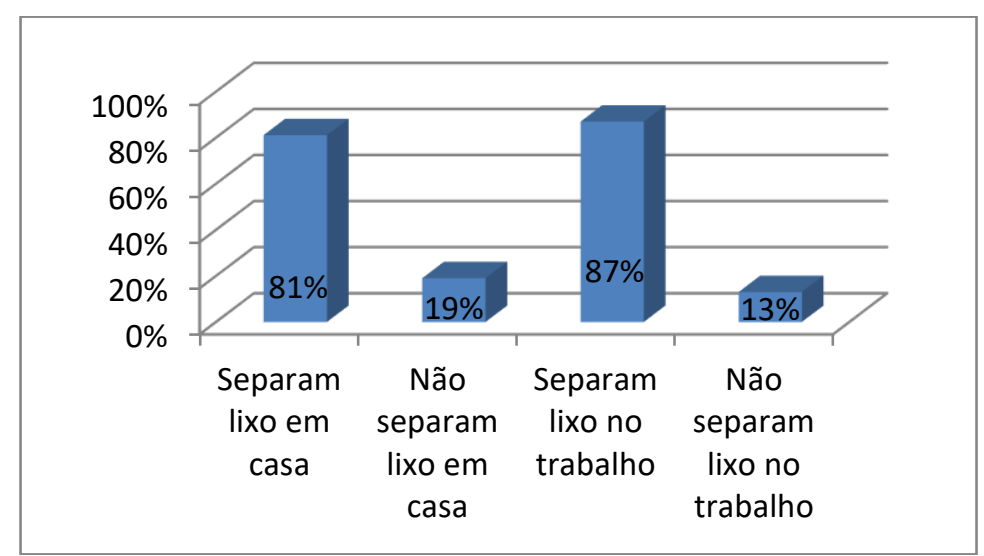

Figura 6: Separação do lixo em casa e no trabalho, ambos os sexos, Cidade de Toledo, Paraná. Fonte: Dados desta pesquisa.

Nas questões, além da pergunta objetiva, foi incluído um questionamento subjetivo, propositadamente, para que se pudesse analisar de forma qualitativa as mesmas respostas objetivas.

Inicialmente, em relação à questão da separação, pôde-se notar que, das pessoas que responderam que fazem a separação de lixo reciclável em suas residências, 21 indivíduos alegaram com precisão ser simples o ato de separar, e que todos participam na família, o que poderia demonstrar um alto grau de objetividade, tais como:

Revbea, São Paulo, V. 14, № 1: 29-48, 2019. 
"Todos participam"; "É fácil, logo se cria o hábito";

"Minha família participa e não há dificuldades";

"Todos participam, não existem dificuldades";

"De certo modo é fácil, temos lixos designados para cada tipo";

"Não há dificuldade, pois é fácil, só você ter como educação diária, por exemplo, ter lugar para o lixo orgânico e outro para o reciclável ao lado" (Respostas dos entrevistados).

Percebe-se que os entrevistados se referem à necessidade de que se estabeleçam hábitos, espaços organizados e lixeiras pra cada tipo de resíduos e ainda à importância da educação. Jacobi (2005, p. 241) cita que as práticas emancipatórias são norteadas pelo empoderamento e pela participação social, e apontam "para propostas pedagógicas centradas na mudança de hábitos, atitudes e práticas sociais".

Mas, alguns entrevistados não compreenderam e dois deles deixaram em branco a resposta subjetiva.

Em contrapartida, durante a análise sobre se há ou não coleta especial dos resíduos, as respostas ao questionário revelaram que, tanto na residência, quanto no ambiente de trabalho, 50,9\% (27 indivíduos) responderam que não existe coleta especializada e $35,8 \%$ dos entrevistados (19 indivíduos) responderam que existe coleta especial para lixo reciclável onde moram. Por fim, $13,2 \%$ ( 7 indivíduos) responderam que não sabem dizer se existe coleta especial (Figura 7).

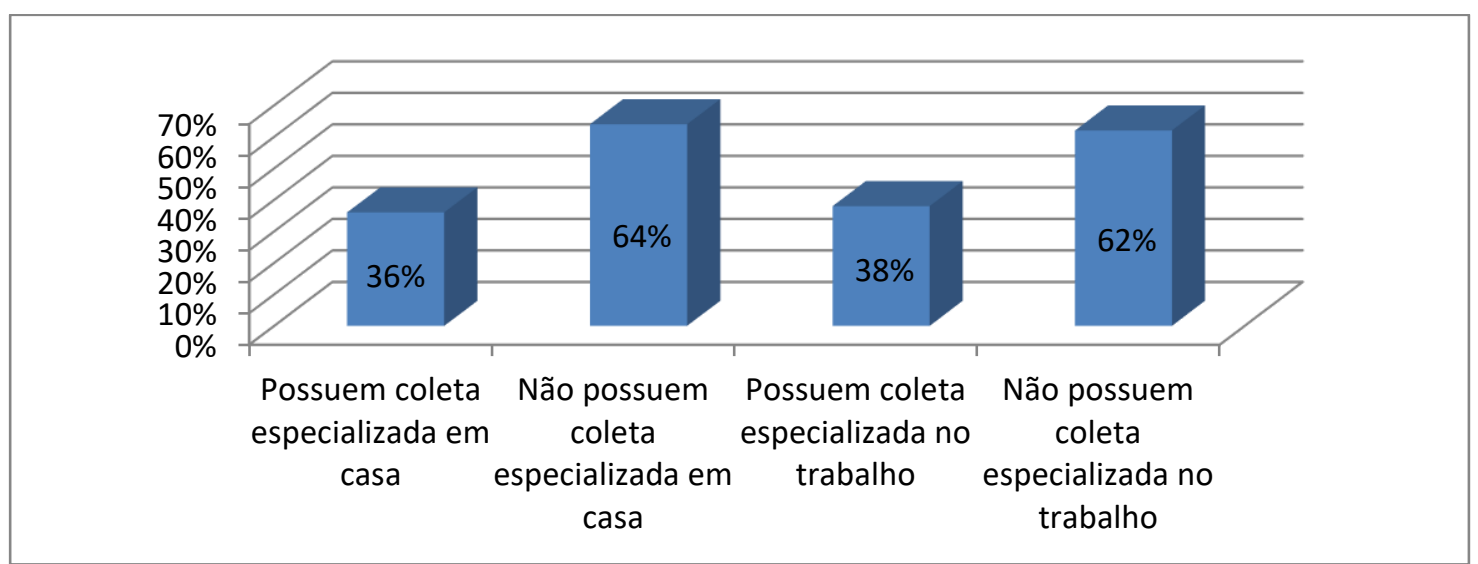

Figura 7: Presença ou ausência de coleta especializada de lixo na residência e no trabalho, Cidade de Toledo, Paraná. Fonte: Dados desta pesquisa.

Vale observar que, se somadas as pessoas que garantem não ter coleta especializada àquelas que não sabem, aproximadamente $64 \%$ de indivíduos informaram não possuir coleta especial em seus bairros de moradia, logo, todo o trabalho de separação do lixo e ou processo educativo seria inútil. Foram obtidas algumas reclamações pela falta de coleta especializada, tais como: 
"É muito importante essa pesquisa porque a gente separa o lixo e os catadores não coletam, se a gente coloca tudo junto eles levam. Portanto, o nosso trabalho não significa nada";

"Moro com amigos da mesma faixa etária, há resistência de hábitos para a separação. O argumento é o de que não há coleta seletiva em nossa rua";

"Fazemos a separação somente de vidros e lâmpadas. A nossa maior dificuldade é que não temos no nosso bairro serviço de coleta de lixo reciclável. No caso de vidros e lâmpadas eu levo pessoalmente nos pontos fixos de coletas da prefeitura";

"É fácil, porém, a empresa coletora não coleta alguns materiais, sacos de lixo com papelão e garrafas de vidro, eles não coletam. Há containers de lixo reciclável apenas no centro, deveriam ter nos bairros, ou se tiver, ser melhor divulgado" (Respostas dos entrevistados).

Suas respostas tornam claro que a reciclagem não pode prosperar se 0 município não tiver uma política e um programa efetivos em resíduos sólidos. Para que ocorra a mudança no modo de pensar e gerir os resíduos, é necessária não apenas a mudança de atitudes dos cidadãos, mas também dos gestores públicos, que são responsáveis pela coleta seletiva e elaboração de estratégias de atendimento à população. Todos necessitam de "aprendizagens sensíveis, compreender as relações entre a sociedade e a natureza e intervir nos problemas e conflitos ambientais, a fim de contribuir para uma mudança de valores e atitudes, formar um sujeito capaz de identificar e problematizar as questões socioambientais e agir sobre elas" (KLUNK et al., 2018, p.13, apud CARVALHO, 2012).

Ainda, algumas pessoas alegaram possuir coleta especializada em suas residências, mas não suficientes, e outras dificuldades gerais.

"Toda família participa, a dificuldade é que a coleta é realizada apenas uma vez por semana";

"Existe muita dificuldade, pois o espaço é pequeno e necessita de containers para armazenamento";

"A família toda não participa, aí se torna um pouco difícil" (Respostas dos entrevistados).

Vale ressaltar a importância de acompanhar e avaliar a eficiência e a eficácia do programa de resíduos sólidos para que o cidadão possa se comprometer em separá-los para a coleta seletiva dos resíduos. A Educação Ambiental não pode ser eficaz se não for acompanhada de um bom programa de gestão, em todas as áreas ambientais. 
Nesse sentido, Klunk et al. (2018, p.13) evocam Sorrentino (1998) ao ressaltarem um desafio que a educação ambiental tem para "resgatar 0 desenvolvimento de valores e comportamentos como confiança, respeito mútuo, responsabilidade, compromisso, solidariedade e iniciativa, e estimular uma visão global e crítica das questões ambientais".

Finalmente, das pessoas que responderam que não fazem a separação, duas argumentaram que não separam porque não há coleta especializada, tais como:

"Não fazemos porque não tem coleta";

"Não, não há separação. É fácil fazer a separação, porém as pessoas não julgam necessário fazer tal separação. Além da falta de conhecimento / entendimento não há estrutura pública que incentive a separação e coleta de lixo de forma produtiva" (Respostas dos entrevistados).

E quando falamos sobre a coleta especializada dentro das empresas, $47,1 \%$ (25 indivíduos) responderam que não existe coleta especializada, todavia, $37,7 \%$ dos entrevistados (20 indivíduos) responderam que existe coleta especial para lixo reciclável onde trabalham, e 13,2\% (7 indivíduos) responderam que não sabem dizer se existe coleta especial. Ainda, 1,8\% (um indivíduo) não respondeu nada na questão (Figura 7).

Vale destacar que muitos dos que responderam sim (que ocorre coleta especial no Parque Moveleiro) frisaram ser por conta da própria empresa, ou seja, a partir de empresas particulares e contratadas, e não de forma pública. Assim, caracteriza-se uma preocupação de algumas indústrias locais em dar destino correto aos lixos separados. Em contrapartida, os dados demonstram o descaso da maioria das indústrias e dos administradores, que não fazem coleta especial.

Portanto, se somadas as pessoas que garantem não ter coleta especializada com as que não sabem, aproximadamente $62 \%$ dos indivíduos demonstraram não possuir coleta especial em seus ambientes de trabalho.

\section{Análises Quali-quantitativas com base no nível de Escolarização}

As análises iniciaram com foco na escolarização e na separação de lixo reciclável dentro da própria residência. Dos 19 entrevistados com Ensino Superior, $89,4 \%$ declararam separar o lixo (17 indivíduos). Na faixa do Ensino Médio, dos 23 entrevistados, 82,6\% (19 indivíduos) declararam separar o lixo. No Ensino Fundamental, nove foram entrevistados e $77,7 \%$ (7 indivíduos) declararam separar o lixo. Dos dois entrevistados que declararam não possuir qualquer escolaridade completa, ou seja, não ter finalizado o Ensino Fundamental, 50,0\% (um indivíduo) declarou separar o lixo. Estes números parecem apontar uma correlação de que quanto maior o nível de escolaridade, maior a sensibilidade com o meio ambiente e a atitude de separar o lixo (Figura 8).

revista brasileira educação ambiental 
Dentre os desafios para a Educação Ambiental, Tristão (2002) pontua quatro: 1) enfrentar a multiplicidade de visões; 2) superar a visão do especialista; 3) superar a pedagogia das certezas e 4) superar a lógica da exclusão e das desigualdades sociais. Em busca de uma leitura do mundo do ponto de vista ambiental, mobilizando sensibilidades afetivas e capacidades cognitivas para estabelecer uma mediação para múltiplas compreensões da experiência do indivíduo e dos coletivos sociais em suas relações com o ambiente (CARVALHO, 2012; KLUNK; MAZZARINO; TURATTI, 2018).

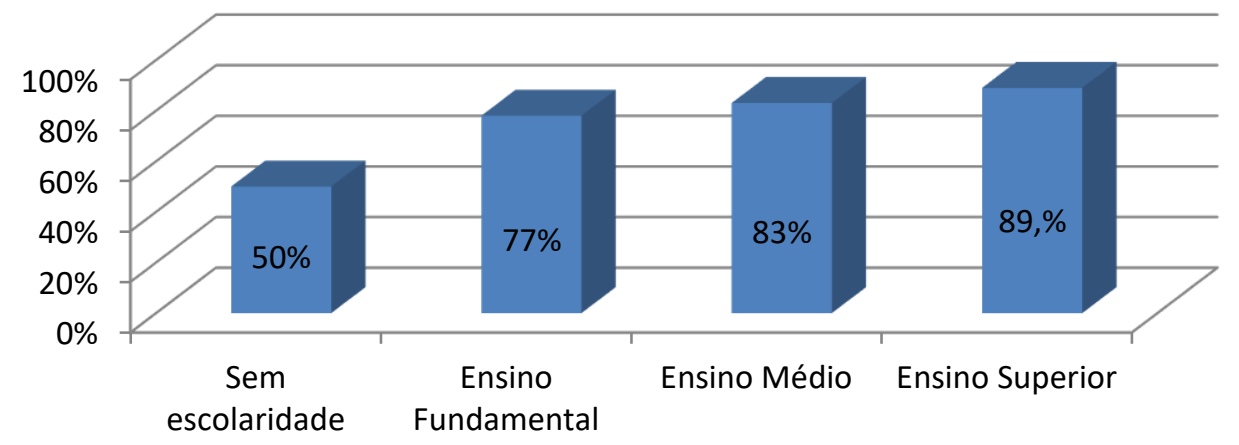

Figura 8: Separação do lixo em casa pelo nível de escolaridade, Cidade de Toledo, Paraná.

Fonte: Dados desta pesquisa.

$\mathrm{Na}$ questão em que foi abordada a separação de lixo reciclável nas empresas onde estes entrevistados atuam, no nível do Ensino Fundamental dos 9 entrevistados, $100,0 \%$ declararam que o lixo é separado nas empresas. Dos participantes que possuem o Ensino Médio (23 entrevistados), 86,9\% (20 indivíduos) declararam separar o lixo. E os entrevistados com Ensino Superior (19 entrevistados), 84,2\% declararam separar o lixo (16 indivíduos), e dos dois entrevistados que declararam não possuir escolaridade completa, ou seja, não ter finalizado o Ensino Fundamental. Um indivíduo $(50,0 \%)$ declarou que o lixo é separado na empresa onde ele trabalha, conforme mostra a Figura 9.

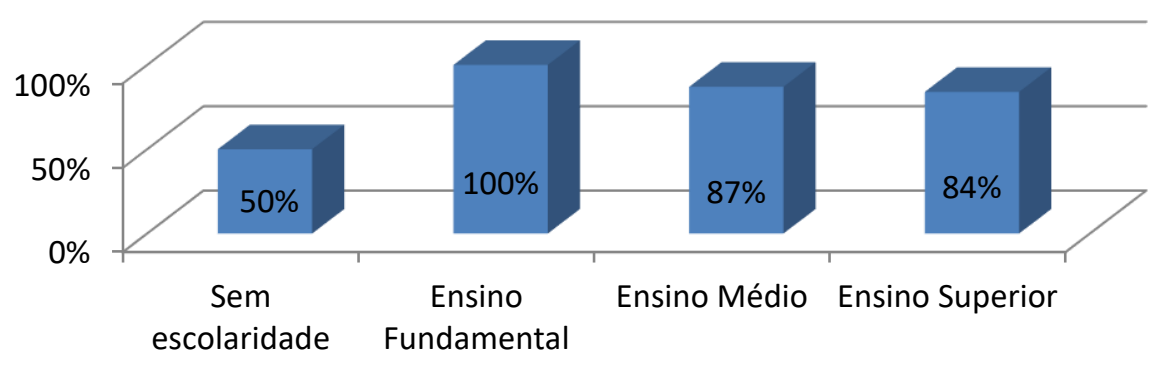

Figura 9: Separação do lixo no trabalho pelo nível de escolaridade, Cidade de Toledo, Paraná. Fonte: Dados desta pesquisa. 
$\mathrm{Na}$ opção em que se aborda a separação no ambiente de trabalho, já não ocorre correlação entre o nível de estudo e a preocupação com a separação do lixo no ambiente de trabalho. Neste caso, a iniciativa ou programas de coletas seletivas nas empresas se deve aos administradores e gerentes do local e não propriamente ao funcionário, o que poderia explicar a falta de nexo ou correlação destes números.

Sobre a terceira questão, quando foi perguntado se é feita a separação de lixo reciclável no ambiente de trabalho e depois, como exatamente ela é feita e organizada, dos que responderam que sim, apenas dois não souberam ou não quiseram descrever como ocorria essa separação.

Destaca-se que a maioria respondeu ser um ato generalizado onde todos participam, com locais adequados para o descarte de cada tipo de resíduo. E, posteriormente, definiram a coleta como adequada para os mesmos. Isso demostrou que, na maioria das respostas, existem uma possível realidade dos fatos e veracidade das suas afirmações. Tais respostas ficam evidenciadas em alguns exemplos como:

"Nós organizamos em um determinado lugar apropriado, depois vem a empresa que faz a coleta correta";

"Todos nós, ela é feita em equipe";

"Somos nós colaboradores mesmo que organizamos a separação do lixo reciclável, é feito a separação dos papéis, plásticos, etc.";

"Todos os funcionários, ao longo do dia separamos o lixo reciclável em uma caixa, e jogamos ao fim do dia em um contêiner destinado a isto, e o lixo orgânico colocamos separado";

"Todos os funcionários separam na hora de descartar";

"Todos os colaboradores são responsáveis pela organização. Cada colaborador leva o material reciclável que gerou no seu turno para o coletor específico" (Respostas dos entrevistados).

Em contrapartida, sete entrevistados alegaram que a separação fica por responsabilidade apenas de uma pessoa. Muitas vezes o zelador ou quem cuida da limpeza, ou até mesmo os proprietários, tais como "o rapaz da limpeza, é feita por classificação dos produtos"; "o responsável pelo setor"; "o proprietário"; "a separação é feita pela responsável pelos serviços gerais". Percebe-se por estas respostas que, nestes casos, demonstram pouca possibilidade de que a coleta seletiva ocorra a contento nestas empresas.

Dando sequência, foi perguntado se o entrevistado avalia o meio ambiente como importante para sua vida. Percebe-se que, nas respostas, não ocorreram diferenciações entre os níveis escolares, visto que 100,0\% (53 indivíduos) responderam que sim, ou seja, julgam o meio ambiente importante. De todos os entrevistados, cinco não souberam ou não quiseram argumentar o porquê do 
meio ambiente ser importante.

Porém, foram também observadas divergências de nível e sensibilidade reais quando abordadas as respostas subjetivas. A grande maioria estabeleceu adequadas concepções, quando descreveram fundamentalmente que sem meio ambiente não há vida, tais como:

"Sem meio ambiente, sem vida. A lógica é simples, necessitamos de água, ar, luz solar e alimentos. A inexistência do meio ambiente impossibilitaria a existência de vida, já que é no meio ambiente que se desdobram as sociedades".

"O meio ambiente nos fornece tudo o que é necessário para a evolução e sustentação dos seres vivos";

"É importante porque não sou o único que uso. E no futuro meus filhos e netos vão utilizar mais do que nós";

"Simplesmente porque faz parte da nossa vida, todos os recursos que necessitamos veem dele e todos nós devemos ser responsáveis por cuidar dele";

"Além de ser a nossa morada, o meio ambiente é o provedor de todos insumos necessários a vida";

"Sem ele não podemos sobreviver";

"Acredito que somos reflexo do que comemos e do ambiente em que vivemos" (Respostas dos entrevistados).

Foram obtidas também visões mais simplistas e um tanto quanto distorcidas, tais como "é importante para nossa respiração principalmente"; "porque ele afeta nossa vida, inclusive a economia, um meio ambiente saudável permite a abundância das coisas, o que faz diminuir os preços". Além destas possíveis visões um tanto quanto afetadas e ofuscadas, que parecem ter como base apenas o pilar econômico, visar lucro, uso ou simplesmente o bem-estar dos humanos.

Por fim, na questão quando perguntado se os recursos são ou não infinitos, Figura 10, parece não haver evidências quanto a existência de relações diretas entre o nível de estudo com maior sensibilidade às questões ambientais, como a limitação dos recursos naturais.

Em se tratando da limitação dos recursos naturais, dos entrevistados que têm o Ensino Médio (23 entrevistados), 91,3\% (21 indivíduos) declararam que os recursos não são ilimitados. E os que têm Ensino Superior (19 entrevistados), $84,2 \%$ (16 indivíduos) declararam não serem ilimitados os recursos. Para os entrevistados com Ensino Fundamental, dos 9 entrevistados, apenas 33,3\% (3 indivíduos) declararam que os recursos não são ilimitados e dos dois entrevistados que declararam não possuir qualquer escolaridade concluída, ou seja, não ter finalizado o Ensino Fundamental, 100,0\% (dois indivíduos) declararam que os recursos não são infinitos.

Revbea, São Paulo, V. 14, № 1: 29-48, 2019. 


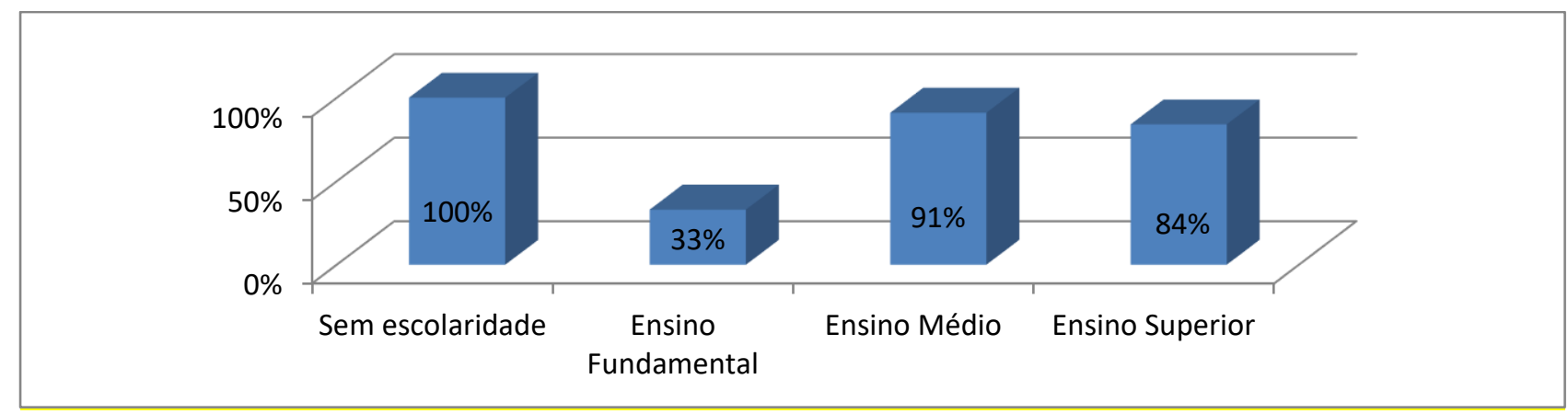

Figura 10: Recursos vistos como algo finito, Cidade de Toledo, Paraná.

Fonte: Dados desta pesquisa.

Do total, a maioria $(78,2 \%)$ considera que os recursos não são infinitos. Assim, foi perguntado o que fez com que eles chegassem a essa resposta ou posicionamento, e foram obtidas desde respostas bem curtas e simplistas, tais como: "nada é ilimitado"; "nada é infinito"; "temos que cuidar, pois nada pode ser infinito"; até respostas mais elaboradas e com um teor de conhecimento um pouco maior, tais como:

"Não são infinitos, são necessários cuidado e controle para que não se esgotem";

"Sem nos preocuparmos com os nossos lixos, estaremos sobrecarregando o planeta e assim o que temos nele, água, ar, alimento";

"O mau uso de recursos naturais, desperdícios de água, mau cuidado do meio ambiente" (Respostas dos entrevistados).

Estes participantes demonstram compreender o gerenciamento e a preservação dos recursos para evitar esgotamento, contaminação, mau uso e descuido com o meio ambiente.

Foram obtidas também respostas com alto nível de sensibilidade:

"Ao levar em conta o contexto de uma sociedade de consumo desenfreado. Não há preocupação por parte das empresas, esfera pública ou civil, em manter um consumo e produção consciente, ao oposto, se incentiva a renovação das mercadorias e a atualização das mesmas, mas não a reciclagem";

"Enquanto se visar ao lucro em larga medida, o meio será predado pela atual configuração da sociedade global";

"Existem ciclos naturais de reposição de recursos em cada fonte, caso a demanda exceda a taxa natural de reposição haverá potencial depleção no local. Ou seja, contaminação ou consumo indiscriminados podem resultar no esgotamento dos recursos naturais necessários à vida" (Respostas dos entrevistados).

Revbea, São Paulo, V. 14, № 1: 29-48, 2019. 
Sensibilidades que dependem do "resgate de valores da solidariedade, da inclusão e da reverência; superação do conceito fechado de desenvolvimento sustentável e ética do cuidado" (BOFF, 2002, p. 239).

Ainda, foram obtidas algumas respostas dos participantes que alegaram chegar às suas conclusões devido aos exemplos de outros locais tais como "pois temos exemplos em outras regiões onde falta água, por exemplo, e a demanda que cada vez mais aumenta influencia diretamente nisso"; e também através de jornais, rádio e mídias em geral, tais como "vemos em jornais, revistas e todos os meios de comunicação a falta de água no Planeta".

Cinco questionários foram também contabilizados, dos quais o entrevistado respondeu que não acreditava serem infinitos os recursos, porém, não soube ou não quis responder à questão subjetiva, deixando-a em branco; Duas pessoas responderam "não sei", das quais uma delas respondeu o seguinte na questão subjetiva: "se cuidarmos mais da natureza, não jogando lixo em locais inadequados, será infinita". Vemos que esta resposta tem seus equívocos, pois muitos minerais já estão quase esgotados e a coleta seletiva e a reciclagem contribuem para diminuir a quantidade de extração de alguns produtos.

Assim, nesta temática, os dados apontam a necessidade de trabalhos de conscientização e sensibilidade da população em geral e uma formação continuada em educação ambiental nas nossas escolas, a fim de que se atenda à legislação atual que obriga a todos os níveis e modalidades de ensino alcançarem a formação dos educandos quanto aos princípios da Educação Ambiental.

\section{Análises Quali-quantitativas com base nas Influências do Ambiente de Trabalho}

Com foco no ambiente de trabalho e na tentativa de imaginar que existam relações entre as pessoas que separam lixo reciclável em casa com o incentivo dentro das empresas onde trabalham, conforme Figuras 11 e 12.

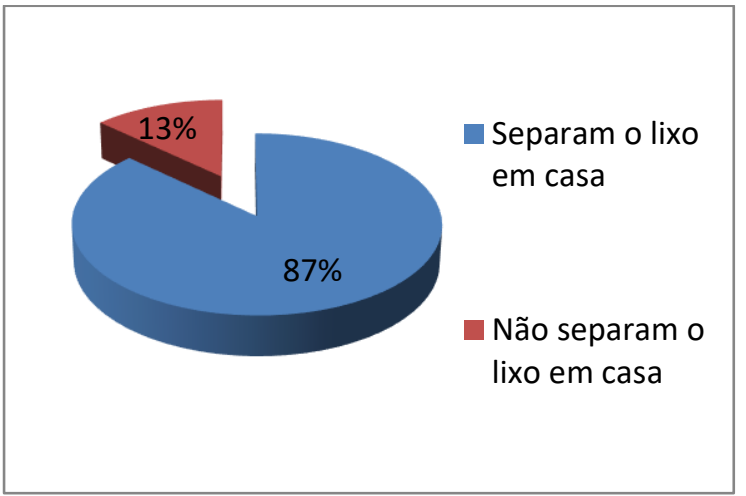

Figura 11: Separam lixo em casa, trabalhando em empresas que também separam. Cidade de Toledo, Paraná.

Fonte: Dados desta pesquisa.

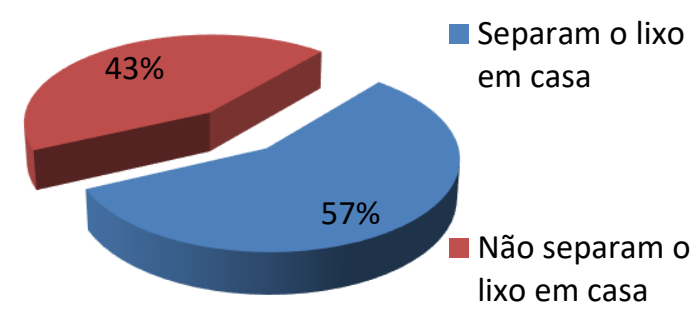

Figura 12: Separam lixo em casa, trabalhando em empresas que não separam. Cidade de Toledo, Paraná.

Fonte: Dados desta pesquisa. 
Observa-se que dos 46 entrevistados que possuem separação de lixo nos seus ambientes de trabalho, 86,9\% (40 indivíduos) também separam o lixo em suas residências. Em contrapartida, dos sete indivíduos entrevistados que não possuem separação de lixo nos seus ambientes de trabalho, apenas 57,1\% (quatro indivíduos) fazem separação em suas residências. Aqui ocorre, portanto, uma nítida correlação de incentivo às vidas particulares pelos exemplos de seus ambientes de trabalho e ou de suas vidas particulares para seu trabalho.

Quando analisada a questão 6, na qual se abordam os recursos naturais como finitos ou infinitos, conforme mostram as Figuras 13 e 14. Dos 46 indivíduos que trabalham em ambientes com separação de lixo, 78,2\% (36 indivíduos) acreditam que os recursos sejam finitos. Por outro lado, dos sete indivíduos que trabalham em ambientes sem separação de lixo, 85,7\% (seis indivíduos) também acreditam que os recursos sejam finitos. Isso não demonstrou possível a correlação entre as influências do ambiente de trabalho com a sensibilidade e noções ambientais perante os recursos naturais.

No entanto, o número de participantes que compreendem a finitude dos recursos naturais foi alto, com respectivamente $78 \%$ e $85 \%$ dos trabalhadores.

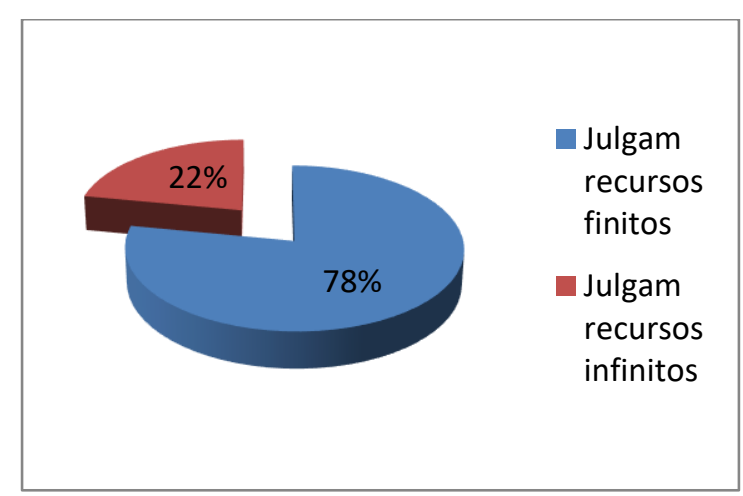

Figura 13: Percepção dos profissionais sobre a finitude dos recursos naturais em relação às empresas que realizam a separação dos resíduos, Cidade de Toledo,

Paraná. Fonte: Dados desta pesquisa.

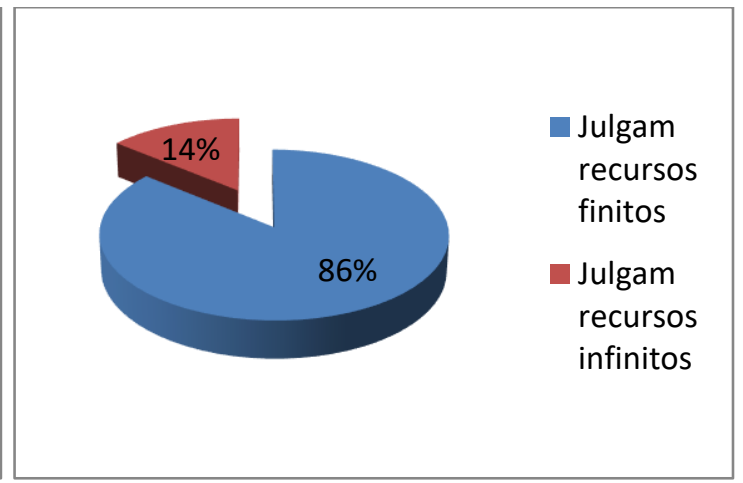

Figura 14: Percepção dos profissionais sobre a finitude dos recursos naturais em relação às empresas que não realizam a separação dos resíduos, Cidade de Toledo,

Paraná. Fonte: Dados desta pesquisa.

Ao buscar compreender até que ponto pode-se depreender que pessoas com maior escolaridade deveriam demonstrar maior sensibilidade e atitudes politicamente corretas em relação às questões ambientais, buscou-se pensar que a Educação Ambiental enfatiza aspectos comunitários e populares ao permitir "identificar conflitos e problemas concernentes às relações das populações com seu entorno, a fim de melhorar as condições ambientais e valorizar as práticas culturais locais bem como gerar maior capacidade para resolver problemas" (KLUNK; MAZZARINO; TURATTI, 2018).

A maior escolaridade deve formar um profissional considerado por Carvalho (2000) como o sujeito ecológico que assume uma bagagem de experiência em decorrência de seus pertencimentos, do seu ativismo ecológico, 
e de sua ação política profissionalizada, que compreende as consequências ambientais das suas escolhas e é capaz de decidir sobre a qualidade de vida das populações. Inspirados em Carvalho (2012), é possível dizer que esta é uma aprendizagem que ultrapassa a fronteira entre a teoria e a prática profissional.

Ainda, enfatiza-se a necessidade de um modelo em cada empresa que permita a adaptação dos procedimentos internos, além de uma seleção das atividades gerenciais e operacionais, as quais poderão atender às necessidades próprias de cada indústria. Um modelo que atue sempre com pró-atividade e inteligência de seus trabalhadores na logística de resíduo, no processo de coleta, manipulação, controle, armazenamento, transporte, tratamento e destinação final de todo resíduo gerado.

\section{Considerações Finais}

Observou-se que, em síntese, aproximadamente $87 \%$ das pessoas trabalham em empresas que separam o lixo, e $81 \%$ delas alegam separar o lixo reciclável em suas residências. Em contrapartida, foram contabilizadas apenas $36 \%$ de pessoas que afirmam receber coleta especializada de lixo reciclável em suas residências e $38 \%$ de empresas que recebem coleta especializada, e em sua maioria, de forma privada e não pública.

Tal situação demonstra não somente a ineficácia desta separação por parte da população, mas também possível desânimo e falta de hábito da mesma por separar e não obter respaldo do município. Salienta-se, portanto, a necessidade de mudanças urgentes dos gestores municipais para não apenas desenvolver programas de Educação Ambiental que buscam despertar a conscientização da população, mas o estabelecimento de programas com práticas de ações corretas de coleta e destino dos resíduos.

Em análise sobre as possíveis correlações pressupostas nos objetivos deste trabalho, foi possível estabelecer uma forte tendência àqueles que possuem maior nível ou grau de escolaridade com maior sensibilidade às questões ambientais, tais como a separação de lixo. Foi possível verificar nessa mesma vertente também dentro dos ambientes de trabalho, onde um número muito maior de pessoas que trabalham em empresas que realizam a separação de lixo também mantêm essa prática em suas casas.

$\mathrm{Na}$ análise das respostas objetivas com as reafirmações pelas respostas subjetivas, a maioria se mostrou coerente e demonstra que foram respostas idôneas que representam a realidade de suas práticas diárias.

Ainda, ficou estabelecido que todos acreditam que o meio ambiente é importante, apesar de alguns com visões bastante simplistas, sem demonstrar terem noções sobre as interações para a coexistência dos seres vivos no Planeta e as reais dependências do ambiente para as nossas vidas.

Registrou-se que $79 \%$ dos entrevistados acreditam que os recursos são finitos, o que de certa forma ainda evidencia uma parcela de $21 \%$ de pessoas que acreditam que os recursos são eternos. Isso talvez demonstre que mais Revbea, São Paulo, V. 14, № 1: 29-48, 2019. 
ações sociais, educacionais e interdisciplinares de educação ambiental sejam necessárias para essa população.

Não foi possível fazer correlação do nível de escolaridade e nem do ambiente de trabalho com noções relacionadas à limitação dos recursos naturais a partir dos resultados. Nesta vertente, talvez sejam necessários trabalhos que melhorem a Educação Ambiental realizada em todos os níveis de ensino, conforme determina a Política Nacional de Educação Ambiental Brasileira, Lei no 9795/1999, bem como as capacitações com gestores das empresas sobre suas responsabilidades de preservação dos recursos naturais.

O presente estudo considera importante não traçar conclusões que possam ser precipitadas, talvez pelo baixo número de entrevistados (53) ou até mesmo pela metodologia simples. Mas, alerta e levanta a necessidade de mais estudos que possam evidenciar de forma mais explícita essas carências e dificuldades da população não somente em Parques Industriais, mas em toda a cidade de Toledo, PR e demais municípios brasileiros.

Fica nítido que a sensibilidade individual perante a Educação Ambiental e o Meio Ambiente é não apenas uma responsabilidade da escola, mas de toda a sociedade. São inúmeras as influências que o cidadão recebe e todos devem exercer seus direitos e deveres perante o meio ambiente. Cada indivíduo deve fazer sua parte e cobrar com ênfase nas autoridades responsáveis que façam a parte delas. Pois, sem um programa eficiente de coleta seletiva e destinação adequada, não existe êxito na reciclagem nem na preservação dos recursos naturais do Planeta.

\section{Referências}

ALVES, A.T.J.; HENDGES, C.R.; SANDER, I.T.; PAZ, D. Reciclagem: educar para conscientizar. Seminário Interinstitucional de Ensino, Pesquisa e Extensão, v. 18, 2012.

AMARO, A.; PÓVOA, A.; MACEDO, L. A arte de fazer questionários. Porto, Portugal: Faculdade de Ciências da Universidade do Porto, 2005.

BEDANI, M. O impacto dos valores organizacionais na percepção de estímulos e barreiras à criatividade no ambiente de trabalho. Revista de Administração Mackenzie, v.13, n. 3, p. 150, 2012.

GOOGLE. Maps. Disponível em: <https://www.google.com.br/maps/place/R.+ Ant\%C3\%B4nio+Comarela, $+4+-+5 \%$ C3\%A30+Francisco, + Toledo++PR,+85905-500/@-24.7007758,-53.7417892,1066m/ data=!3m1!1e3!4m5!3m 4!1s0x94f395f94c5b8101:0x7daa20ba1e2bd90e!8m2!3d-24.7017164!4d53.7416846>. Acesso em: 10 Jul. 2017.

IBGE - Instituto Brasileiro de Geografia e Estatística. Banco de Dados - Cidades. Disponível em:<https://cidades.ibge.gov.br/v4/brasil/pr/toledo/panorama>. Acesso em: 12 Jul. 2017. 
KLUNK, L.; MAZZARINO, J.M.; TURATTI, L. O Educador Ambiental do Projeto Cultivando Água Boa da Bacia Hidrográfica do Paraná III. REVBEA, São Paulo, v. 13, n. 3, p. 10-25, 2018.

LOMASSO, A.L.; SANTOS, B.R.; ANJOS, F.A.S.; ANDRADE, J.C.; SILVA, L.A.; SANTOS, Q.R.; CARVALHO, A.C.M. Benefícios e desafios na implementação da reciclagem: um estudo de caso no centro mineiro de referência em resíduos. Revista Pensar Gestão e Administração, v. 3, n. 2, 2015.

MANZATO, A.J.; SANTOS, A.B. A elaboração de questionários na pesquisa quantitativa. Departamento de Ciência de Computação e Estatística-IBILCEUNESP, 2012.

PARANÁ. Prefeitura Municipal - Toledo. Disponível em: $<$ https://www.toledo.pr.gov.br/portal/cidade-conheca-toledo/toledo-emnumeros >. Acesso em: 13 Jul. 2017.

PEIXOTO, K.; CAMPOS, V.B.G.; D'AGOSTO, M.A. A coleta seletiva e a redução dos resíduos sólidos. Rio de Janeiro: Instituto Militar de Engenharia, 2005.

SAHEB, D.; DA LUZ, A.A. As representações de meio ambiente de professores e alunos e a pedagogia de projetos: um estudo de caso em classes de alfabetização. REMEA - Revista Eletrônica do Mestrado em Educação Ambiental, v. 16, 2012.

TRINDADE, N.A.D. Consciência ambiental: coleta seletiva e reciclagem no ambiente escolar. Enciclopédia Biosfera, v. 7, n. 12, p. 1-15, 2011.

VASCONCELOS, A.F. Felicidade no ambiente de trabalho: exame e proposição de algumas variáveis críticas. Revista Eletrônica de Administração, v. 10, n. 1, 2004.

ZAMCOPÉ, F.C.; ENSSLIN, L.; ENSSLIN, S.R. Construção de um modelo para avaliação da sustentabilidade corporativa: um estudo de caso na indústria têxtil. 2009. Tese de Doutorado. Universidade Federal de Santa Catarina, Centro Tecnológico, Programa de Pós-Graduação em Engenharia de Produção, Florianópolis, SC. 